\title{
Association between Regular Exercise and Dietary Intake among Japanese Young Adults Aged 18-24 Years: A Cross-Sectional Study
}

\author{
Yuya KAKUTANI $^{1}$, Saori KAMIYA ${ }^{1}$ and Naomi OMI ${ }^{1,2, *}$ \\ ${ }^{1}$ Graduate School of Comprehensive Human Science, and ${ }^{2}$ Faculty of Health and Sport Sciences, \\ University of Tsukuba, Ibaraki 305-8574, Japan
}

(Received December 4, 2014)

\begin{abstract}
Summary The aim of this study was to examine the association between regular exercise and dietary intake in Japanese young adults. A cross-sectional study was performed between May 2013 and July 2013 in universities, colleges, and technical schools located in Ibaraki, Kanagawa, Tokyo, and Nara in Japan. The final sample comprised 654 students, 473 females and 181 males, aged 18-24 y. Regular exercise and dietary intake were assessed using validated self-reported questionnaires. Logistic regression analyses were applied to examine the association between regular exercise and dietary intake. A total of $18 \%$ females and $40 \%$ males spent $\geq 5 \mathrm{~h}$ per week exercising. Females who spent $\geq 5 \mathrm{~h}$ per week exercising were likely to have a higher intake of fruits (odds ratio (OR), 1.84; 95\% confidence interval (CI), 1.09-3.13) and a lower intake of cereals (OR, 0.57; 95\% CI, 0.33-0.97) than were those who spent $<1 \mathrm{~h}$ per week. Males who spent $\geq 5 \mathrm{~h}$ per week exercising were more likely to have a higher intake of fish and shellfish (OR, 2.69; 95\% CI, 1.07-6.77) than those who spent $<1 \mathrm{~h}$ per week. In conclusions, young adults who spent $\geq 5 \mathrm{~h}$ per week exercising had a higher intake of fruits among females, and a higher intake of fish and shellfish among males than those who spent $<1 \mathrm{~h}$ per week. The present findings suggested food group intakes associated with regular exercise in Japanese young adults.
\end{abstract}

Key Words regular exercise, questionnaire, diet, fruits, fish and shellfish

Physical activity and dietary intake are two of the main contributors to health. Physical activity can be divided into exercise and non-exercise. Exercise is defined as planned, structured, and repetitive bodily movement done to improve or maintain one or more components of physical fitness (1). Regular exercise contributes not only to the prevention of chronic disease but also improves mental well-being $(2,3)$ and musculoskeletal condition (4). In contrast, a lack of physical activity, including exercise, and poor dietary habits are considered to be fundamental risk factors for non-communicable diseases $(5,6)$.

In Japan, the Ministry of Health, Labour and Welfare set reference values for physical activity and exercise (7). The National Health and Nutrition Survey in Japan (8) revealed that only $19.7 \%$ of individuals aged 20-29 y achieved the recommended amount of exercise of $\geq 30 \mathrm{~min}$ per time, twice or more per week for at least $1 \mathrm{y}$ (7). This survey also indicated that young adults have poor dietary habits, as characterized by a high fat energy ratio, the habit of skipping breakfast, and a low consumption of fruits and vegetables (8). Both increased physical activity, including exercise, and improved dietary habits are important public health tasks in Japanese young adults.

*To whom correspondence should be addressed.

E-mail: ominaomi@taiiku.tsukuba.ac.jp
Previous studies reported an association between physical activity and dietary intake (9-11). In the United Kingdom, the SPEEDY study (Sport, Physical activity and Eating behavior: Environmental Determinants in Young People) was established to examine the levels of physical activity and dietary behavior in a large population-based sample of British children aged 9-10 y (12). This study suggested that increased physical activity, which was measured objectively, was associated with an increased intake of fruits and vegetables, and decreased intake of fizzy drinks and savory snacks (9). Moreover, the likely association between physical activity and diet was examined in Saudi Arabia (10), as well as several European countries (11). This suggests that dietary and physical activity behaviors often do not occur in isolation but are correlated with each other. In addition, several previous studies reported the effects of exercise on energy-providing nutrient intake $(13,14)$, although inconsistent results were reported (15). To effectively promote changes that enhance both health behaviors, it is important to assess the association between exercise and dietary intake. However, because most studies reported to date included predominantly children or adolescents, this association in adults is unclear (15). In addition, reports that also consider exercise are lacking. Therefore, we performed a cross-sectional study to examine the association between regular exercise and dietary intake in Japanese young adults. 


\section{MATERIALS AND METHOD}

Subjects. A cross-sectional study was performed between May 2013 and July 2013 in universities, colleges, and technical schools located in Ibaraki, Kanagawa, Tokyo, and Nara in Japan. The present study was conducted after receiving approval from the ethics committee of the Faculty of Health and Sport Sciences, University of Tsukuba. This study was performed in accordance with the Declaration of Helsinki. A collaborator at each institution explained the general purpose and outline of the study to 874 subjects. Written informed consent was obtained from all participants. A total of 761 students (collection rate $=87.1 \%$ ) answered the questionnaires.

Subjects for whom data regarding age, height, weight, or regular exercise was missing $(n=13)$, or who were aged over $25 \mathrm{y} \quad(n=25)$ were excluded. Individuals considered likely to have under- or over-reported their energy intake were also excluded (16). This included subjects with a reported energy intake of $<50 \%$ of the energy requirement for the lowest physical activity category according to the recommended Dietary Reference Intakes for Japanese subjects, 2010 (17), or those with a reported energy intake of $\geq 1.5$ times the energy requirement of the highest physical activity category $(n=69)$. The final sample comprised 654 students, 473 females and 181 males, aged $18-24 \mathrm{y}$ (response rate $=85.9 \%$ ).

Assessment of dietary intake. Dietary intake during the preceding month was assessed using a validated brief-type self-administered diet history questionnaire (BDHQ), which is a short version of a validated selfadministered diet history questionnaire (DHQ) $(18,19)$.

The BDHQ estimates the dietary intake of 58 food and beverage items and 99 nutrients with reference to the Standard Tables of Food Composition in Japan (20). The dietary intake of the 58 food and beverage items was categorized according to previously validated food groups (21). The BDHQ was validated for the intake of nutrients and food groups against 16-d weighed dietary records of Japanese adults as the gold standard $(21,22)$. The mean correlation coefficients used in the present study were 0.17-0.52 for the food groups, and 0.270.65 for nutrients $(21,22)$.

Assessment of regular exercise. The subjects were asked the following question: "How much time per week did you usually spend engaging in physical exercise or sports?" The results were self-reported according to the following five categories: " $<1 \mathrm{~h} / \mathrm{wk}, "$ " $1-4 \mathrm{~h} /$ wk," "5-7 h/wk," "8-11 h/wk," and ">12 h/wk." This question was an original question that we created by modifying a single-item question whose validity and reliability were confirmed (23). For data analyses, 5-7, $8-11$, and not less than $12 \mathrm{~h} / \mathrm{wk}$ were combined into a " $\geq 5 \mathrm{~h} / \mathrm{wk}$ " group. The subjects were categorized as either "sedentary" ( $<1 \mathrm{~h} / \mathrm{wk})$, "moderate" (1-4 h/wk), or "active" ( $\geq 5 \mathrm{~h} / \mathrm{wk}$ ) according to regular exercise.

Other variables. The BDHQ also required the subjects to report their birth date, bodyweight, and height. Body mass index (BMI) was calculated as bodyweight divided by the square of height $\left(\mathrm{kg} / \mathrm{m}^{2}\right)$. The subjects also provided details regarding their education (university, college, and technical school) and their living status (alone or with family).

Statistical analysis. Because regular exercise differed between genders, we conducted separate analyses for females and males. Because gender differences existed, the means were compared for continuous values using Student's $t$-tests, and proportions were compared for categorical values using chi-squared tests. Because food group intake had a non-normal distribution, the Kruskal-Wallis tests were used to compare the medians of groups. Food group intake was dichotomized according to gender-specific medians. The median cutoff selection was based on the lack of food group intake recommendations. Logistic regression was used to analyze food group intake as dependent variables and regular exercise as an independent variable; these analyses were adjusted for age (years, continuous), BMI $\left(\mathrm{kg} / \mathrm{m}^{2}\right.$, continuous), living alone (yes or no), and education (university and college or technical school). The "sedentary" group was used as the reference category.

All statistical analyses were performed using IBM SPSS version 20 for Mac software (IBM Corp, Armonk, $\mathrm{NY}$ ). All reported $p$-values were two-tailed, and values $<0.05$ were considered to be statistically significant.

\section{RESULTS}

The characteristics of the 654 young adults categorized by gender are shown in Table 1. Male subjects were taller, heavier, and had a higher mean BMI than females. Most subjects ( $72.7 \%$ females; $54.7 \%$ males) were not living alone. In males and females, respectively, $76.1 \%$ and $70.2 \%$ attended university, and $20.3 \%$ and $15.5 \%$ went to technical school.

Table 2 present the results of the Kruskal-Wallis tests for food group intake according to regular exercise for females and males, respectively. A total of $18 \%$ of females and $40 \%$ of males spent $\geq 5 \mathrm{~h}$ per week exercising. There was an association between regular exercise and the intake of confectioneries in females. The median intake (25th to 75 th percentile) of confectioneries in females in the exercise response categories of " $<1 \mathrm{~h} / \mathrm{wk}$," " $1-4 \mathrm{~h} / \mathrm{wk}$," and " $\geq 5 \mathrm{~h} / \mathrm{wk}$ " was 24.0 (12.8-35.7), 19.4 (11.1-30.9), and 25.0 (13.9-39.3) $\mathrm{g} / 1,000 \mathrm{kcal}$, respectively $(p=0.04)$ (Table 2$)$. There was no association between regular exercise and food group intake in males and females, except for confectioneries in females.

Tables 3 and 4 present the results of logistic regression analysis according to regular exercise and food group intake in females and males, respectively. There were significant associations after adjustment for age, BMI, living alone, and education. Females who spent $\geq 5 \mathrm{~h} /$ wk exercising had a higher intake of fruits (odds ratio (OR), 1.84; 95\% confidence interval (CI), 1.093.13 ) and a lower intake of cereals (OR, 0.57; 95\% CI, 0.33-0.97) than those who exercised for $<1 \mathrm{~h} / \mathrm{wk}$ (Table 4). Males who spent $\geq 5 \mathrm{~h} / \mathrm{wk}$ exercising were likely to have a higher intake of fish and shellfish (OR, 
Table 1. Basic characteristics of 654 Japanese young adults categorized by gender.

\begin{tabular}{|c|c|c|c|}
\hline & Total & Females $(n=473)$ & Males $(n=181)$ \\
\hline Age, y & $19.5(0.1)^{*}$ & $19.4(0.1)$ & $19.8(0.1)$ \\
\hline Body height, cm & $162.1(0.3)$ & $158.6(0.3)$ & $171.3(0.4)$ \\
\hline Body weight, kg & $54.7(0.4)$ & $51.1(0.3)$ & $64.1(0.7)$ \\
\hline BMI, $\mathrm{kg} / \mathrm{m}^{2 \dagger}$ & $20.7(0.1)$ & $20.3(0.1)$ & $21.8(0.2)$ \\
\hline \multicolumn{4}{|l|}{ Living alone, $n(\%)$} \\
\hline Yes & $211(32.3)$ & $129(27.3)$ & $82(45.3)$ \\
\hline No & $443(67.7)$ & $344(72.7)$ & $99(54.7)$ \\
\hline \multicolumn{4}{|l|}{ Education, $n(\%)$} \\
\hline University & $487(74.5)$ & $360(76.1)$ & $127(70.2)$ \\
\hline College & $43(6.6)$ & $17(3.6)$ & $26(14.4)$ \\
\hline Technical school & $124(19.0)$ & $96(20.3)$ & $28(15.5)$ \\
\hline
\end{tabular}

BMI, body mass index.

* Values are expressed as mean (standard error) or number (\%).

$\dagger$ Body mass index was calculated as current bodyweight (kg) divided by the square of body height $(\mathrm{m})$.

2.69; 95\% CI, 1.07-6.77) than those who spent $<1 \mathrm{~h} /$ wk exercising (Table 5).

\section{DISCUSSION}

The results of the present study revealed an association between regular exercise and dietary intake in Japanese young adults aged 18-24 y. Regular exercise of $\geq 5 \mathrm{~h}$ per week was significantly associated with a higher fruits intake and lower cereals intake among females. In males, regular exercise of $\geq 5 \mathrm{~h}$ per week was associated with a higher fish and shellfish intake. Fruits, fish and shellfish intake have been reported to be associated with risk reduction of non-communicable disease $(24,25)$. People who have regular exercise might have preferable dietary habits. To our knowledge, this is the first study in Japan to examine the association between regular exercise and dietary intake in young adults.

The present study revealed that females who spent $\geq 5 \mathrm{~h}$ per week exercising had a higher intake of fruits than those who spent $<1 \mathrm{~h}$ per week exercising. Consistent with these results, previous studies found that higher physical activity, including exercise, was associated with a higher intake of fruits regardless of age or generation (9-11, 26, 27). In children and adolescents, much evidence demonstrated that high physical activity was associated with fruits intake. In a study conducted in European adolescents from 10 European cities, the most active adolescents had a higher intake of fruit and milk than their less active peers (11). In Balearic Island adolescents, active subjects had a more frequent intake of fruit and breakfast cereal compared with their sedentary counterparts (26). In adolescents from Saudi Arabia, Al-Hazzaa et al. found that physical activity was positively correlated with fruit and vegetable intake in both genders (10). In addition, the SPEEDY study revealed an association between higher fruit and vegetable intake and higher physical activity in British Caucasian children (9). In a study of children and adolescents in the Islamic Republic of Iran, a higher fruit and vegetable intake was associated with increased physical activity (27). Moreover, the association between physical activity and intake of fruits was consistent with two previous studies performed in adults $(28,29)$. In French adults, leisure time physical activity was associated with an increased frequency of intake of fruits and vegetables (28). Similarly, a previous study in the United States revealed that an increased intake of fruit and dairy foods was related to increased physical activity in young adults (29). The results of the present study are consistent with these previous studies conducted in adults.

In the present study, we found that males who spent $\geq 5 \mathrm{~h}$ per week exercising had a higher intake of fish and shellfish than those who spent $<1 \mathrm{~h}$ per week. The association between physical activity, including exercise, and fish intake might be unique to males. Although studies examining the relationship of physical activity and fish intake are limited, three studies showed an association similar to that of the present study only in males (11, $28,30)$. Oppert et al. reported that leisure time physical activity was associated with increased fish intake only in males (28). However, the cause of this association being observed only in males is unclear.

In the present study, we found an association between regular exercise of $\geq 5 \mathrm{~h}$ per week and intake of fruits in females and the intake of fish and shellfish in males. It is possible that exercise alters consciousness, and thereby contributes to changes in healthy dietary behavior, such as eating fruit and fish. The Society of Behavioral Medicine proposes multiple health behavior change (MHBC) to promote health and manage disease (31). MHBC can be defined as efforts to promote two or more health behaviors. Success in changing one or more lifestyle behavior might increase confidence or self-efficacy to improve the risk behaviors that individuals generally have low motivation to change. In a 7-y prospective observational study of Japanese males, Nagaya et al. (32) found that increased habitual exercise was associated with smoking cessation. The findings of this study might have resulted from a general health consciousness, increased concern regarding weight manage- 


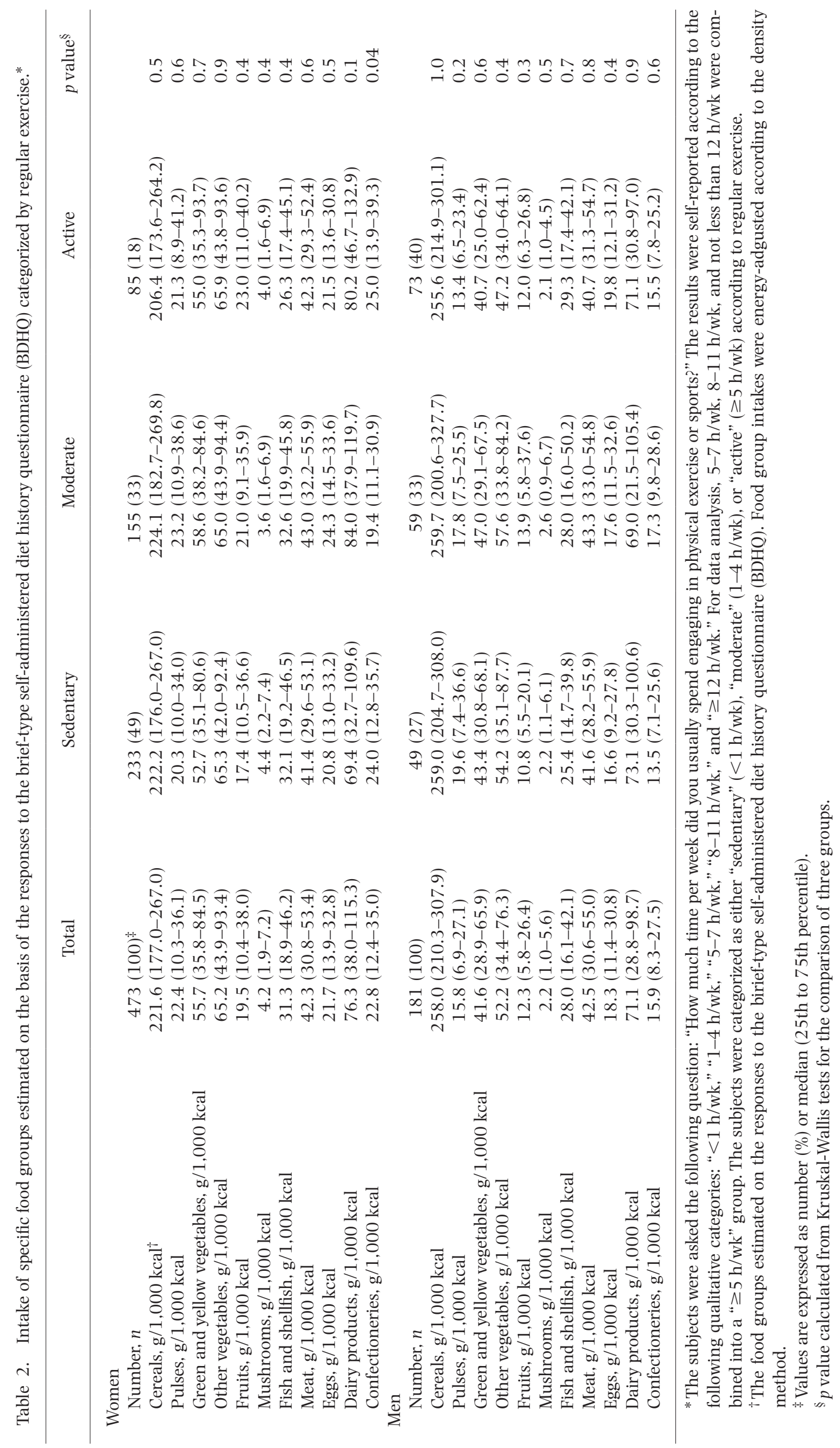


Table 3. Adjusted odds ratios and 95\% confidence intervals the intake of specific food groups categorized by regular exercise in females.*

\begin{tabular}{|c|c|c|c|}
\hline & Sedentary $(n=233)$ & Moderate $(n=155)$ & Active $(n=85)$ \\
\hline \multicolumn{4}{|l|}{ Food groups } \\
\hline \multicolumn{4}{|l|}{ Cereals } \\
\hline Not less than median/less than median ${ }^{\dagger}$ & $118 / 115$ & $83 / 72$ & $36 / 49$ \\
\hline Nonadjusted OR $(95 \% \mathrm{CI})$ & 1.00 (reference) & $1.12(0.75-1.69)$ & $0.72(0.43-1.18)$ \\
\hline Adjusted OR $(95 \% \mathrm{CI})^{\ddagger}$ & 1.00 (reference) & $1.01(0.66-1.54)$ & $0.57(0.33-0.97)$ \\
\hline \multicolumn{4}{|l|}{ Pulses } \\
\hline Not less than median/less than median ${ }^{\dagger}$ & $111 / 122$ & $84 / 71$ & $42 / 43$ \\
\hline Nonadjusted OR $(95 \% \mathrm{CI})$ & 1.00 (reference) & $1.30(0.87-1.95)$ & $1.07(0.65-1.76)$ \\
\hline Adjusted OR $(95 \% \mathrm{CI})^{\ddagger}$ & 1.00 (reference) & $1.36(0.90-2.06)$ & $1.14(0.68-1.91)$ \\
\hline \multicolumn{4}{|l|}{ Green and yellow vegetables } \\
\hline Not less than median/less than median ${ }^{\dagger}$ & $112 / 121$ & $83 / 72$ & $42 / 43$ \\
\hline Nonadjusted OR (95\% CI) & 1.00 (reference) & $0.98(0.46-2.09)$ & $0.77(0.37-1.59)$ \\
\hline Adjusted OR $(95 \% \mathrm{CI})^{\ddagger}$ & 1.00 (reference) & $1.36(0.90-2.08)$ & $1.34(0.79-2.27)$ \\
\hline \multicolumn{4}{|l|}{ Other vegetables } \\
\hline Not less than median/less than median ${ }^{\dagger}$ & $117 / 116$ & $76 / 79$ & $44 / 41$ \\
\hline Nonadjusted OR (95\% CI) & 1.00 (reference) & $0.95(0.64-1.43)$ & $1.06(0.65-1.75)$ \\
\hline Adjusted OR $(95 \% \mathrm{CI})^{\ddagger}$ & 1.00 (reference) & $1.03(0.68-1.57)$ & $1.37(0.81-2.32)$ \\
\hline \multicolumn{4}{|l|}{ Fruits } \\
\hline Not less than median/less than median ${ }^{\dagger}$ & $108 / 125$ & $79 / 76$ & $50 / 35$ \\
\hline Nonadjusted OR $(95 \% \mathrm{CI})$ & 1.00 (reference) & $1.20(0.80-1.81)$ & $1.65(1.00-2.73)$ \\
\hline Adjusted OR $(95 \% \mathrm{CI})^{\ddagger}$ & 1.00 (reference) & $1.34(0.88-2.04)$ & $1.84(1.09-3.13)$ \\
\hline \multicolumn{4}{|l|}{ Mushrooms } \\
\hline Not less than median/less than median ${ }^{\dagger}$ & $121 / 112$ & $74 / 81$ & $42 / 43$ \\
\hline Nonadjusted OR $(95 \% \mathrm{CI})$ & 1.00 (reference) & $0.85(0.56-1.27)$ & $0.90(0.55-1.49)$ \\
\hline Adjusted OR $(95 \% \mathrm{CI})^{\ddagger}$ & 1.00 (reference) & $0.98(0.64-1.50)$ & $1.13(0.67-1.91)$ \\
\hline \multicolumn{4}{|l|}{ Fish and shellfish } \\
\hline Not less than median/less than median ${ }^{\dagger}$ & $121 / 112$ & $81 / 74$ & $35 / 50$ \\
\hline Nonadjusted OR (95\% CI) & 1.00 (reference) & $1.01(0.68-1.52)$ & $0.65(0.39-1.07)$ \\
\hline Adjusted OR $(95 \% \mathrm{CI})^{\ddagger}$ & 1.00 (reference) & $1.22(0.78-1.89)$ & $0.96(0.55-1.67)$ \\
\hline \multicolumn{4}{|l|}{ Meat } \\
\hline Not less than median/less than median ${ }^{\dagger}$ & $111 / 122$ & $83 / 72$ & $43 / 42$ \\
\hline Nonadjusted OR $(95 \% \mathrm{CI})$ & 1.00 (reference) & $1.27(0.84-1.90)$ & $1.13(0.69-1.85)$ \\
\hline Adjusted OR $(95 \% \mathrm{CI})^{\ddagger}$ & 1.00 (reference) & $1.30(0.85-1.97)$ & $1.11(0.66-1.88)$ \\
\hline \multicolumn{4}{|l|}{ Eggs } \\
\hline Not less than median/less than median ${ }^{\dagger}$ & $110 / 123$ & $85 / 70$ & $42 / 43$ \\
\hline Nonadjusted OR (95\% CI) & 1.00 (reference) & $1.36(0.90-2.04)$ & $1.09(0.66-1.80)$ \\
\hline Adjusted OR $(95 \% \mathrm{CI})^{\ddagger}$ & 1.00 (reference) & $1.43(0.92-2.22)$ & $1.09(0.64-1.88)$ \\
\hline \multicolumn{4}{|l|}{ Dairy products } \\
\hline Not less than median/less than median ${ }^{\dagger}$ & $106 / 127$ & $85 / 70$ & $46 / 39$ \\
\hline Nonadjusted OR $(95 \% \mathrm{CI})$ & 1.00 (reference) & $1.46(0.97-2.19)$ & $1.41(0.86-2.33)$ \\
\hline Adjusted OR $(95 \% \mathrm{CI})^{\ddagger}$ & 1.00 (reference) & $1.42(0.94-2.16)$ & $1.27(0.76-2.14)$ \\
\hline \multicolumn{4}{|l|}{ Confectioneries } \\
\hline Not less than median/less than median ${ }^{\dagger}$ & $122 / 111$ & $69 / 86$ & $46 / 39$ \\
\hline Nonadjusted OR (95\% CI) & 1.00 (reference) & $0.73(0.49-1.10)$ & $1.07(0.65-1.77)$ \\
\hline Adjusted OR $(95 \% \mathrm{CI})^{\ddagger}$ & 1.00 (reference) & $0.71(0.47-1.07)$ & $1.02(0.61-1.71)$ \\
\hline
\end{tabular}

OR, odds ratio; CI, confidence interval.

* The subjects were asked the following question: "How much time per week did you usually spend on engaging in physical exercise or sports?" The results were self-reported according to the following five categories: " $<1 \mathrm{~h} /$ wk," "1-4 h/wk," "5-7 h/wk," "8-11 h/wk," and " $\geq 12 \mathrm{~h} /$ wk." For data analysis, 5-7 h/wk, 8-11 h/wk, and not less than $12 \mathrm{~h} /$ wk were combined into a " $\geq 5 \mathrm{~h} / \mathrm{wk}$ " group. The subjects were categorized as either "sedentary" ( $<1 \mathrm{~h} / \mathrm{wk})$, "moderate" (1-4 h/wk), or "active" ( $\geq 5 \mathrm{~h} / \mathrm{wk})$ according to regular exercise.

$\dagger$ Median of food group intake is gender-specific (see Table 2).

$\$$ Adjusted for age (years, continuous), BMI ( $\mathrm{kg} / \mathrm{m}^{2}$, continuous), living alone (yes or no), and education (university, college, or technical school). 
Table 4. Adjusted odds ratios and 95\% confidence intervals the intake of specific food groups categorized by regular exercise in males.*

\begin{tabular}{|c|c|c|c|}
\hline & Sedentary $(n=49)$ & Moderate $(n=59)$ & Active $(n=73)$ \\
\hline \multicolumn{4}{|l|}{ Food groups } \\
\hline \multicolumn{4}{|l|}{ Cereals } \\
\hline Not less than median/less than median ${ }^{\dagger}$ & $25 / 24$ & $30 / 29$ & $36 / 37$ \\
\hline Nonadjusted OR (95\% CI) & 1.00 (reference) & $0.99(0.47-2.12)$ & $0.93(0.45-1.93)$ \\
\hline Adjusted OR $(95 \% \mathrm{CI})^{\ddagger}$ & 1.00 (reference) & $0.96(0.44-2.11)$ & $0.72(0.32-1.63)$ \\
\hline \multicolumn{4}{|l|}{ Pulses } \\
\hline Not less than median/less than median ${ }^{\dagger}$ & $29 / 20$ & $31 / 28$ & $31 / 42$ \\
\hline Nonadjusted OR (95\% CI) & 1.00 (reference) & $0.76(0.36-1.64)$ & $0.51(0.24-1.06)$ \\
\hline Adjusted OR $(95 \% \mathrm{CI})^{\ddagger}$ & 1.00 (reference) & $0.82(0.36-1.86)$ & $0.70(0.30-1.63)$ \\
\hline \multicolumn{4}{|l|}{ Green and yellow vegetables } \\
\hline Not less than median/less than median ${ }^{\dagger}$ & $26 / 23$ & $31 / 28$ & $34 / 39$ \\
\hline Nonadjusted OR $(95 \%$ CI $)$ & 1.00 (reference) & $0.98(0.46-2.09)$ & $0.77(0.37-1.59)$ \\
\hline Adjusted OR $(95 \% \mathrm{CI})^{\ddagger}$ & 1.00 (reference) & $1.10(0.50-2.42)$ & $1.07(0.47-2.43)$ \\
\hline \multicolumn{4}{|l|}{ Other vegetables } \\
\hline Not less than median/less than median ${ }^{\dagger}$ & $25 / 24$ & $34 / 25$ & $32 / 41$ \\
\hline Nonadjusted OR (95\% CI) & 1.00 (reference) & $1.31(0.61-2.80)$ & $0.75(0.36-1.55)$ \\
\hline Adjusted OR $(95 \% \mathrm{CI})^{\ddagger}$ & 1.00 (reference) & $1.36(0.90-2.08)$ & $1.34(0.79-2.27)$ \\
\hline \multicolumn{4}{|l|}{ Fruits } \\
\hline Not less than median/less than median ${ }^{\dagger}$ & $21 / 28$ & $34 / 25$ & $36 / 37$ \\
\hline Nonadjusted OR $(95 \% \mathrm{CI})$ & 1.00 (reference) & $1.81(0.84-3.90)$ & $1.30(0.63-2.69)$ \\
\hline Adjusted OR $(95 \% \mathrm{CI})^{\ddagger}$ & 1.00 (reference) & $2.06(0.92-4.63)$ & $2.02(0.86-4.71)$ \\
\hline \multicolumn{4}{|l|}{ Mushrooms } \\
\hline Not less than median/less than median ${ }^{\dagger}$ & $25 / 24$ & $32 / 27$ & $34 / 39$ \\
\hline Nonadjusted OR (95\% CI) & 1.00 (reference) & $1.14(0.53-2.43)$ & $0.84(0.41-1.73)$ \\
\hline Adjusted OR $(95 \% \mathrm{CI})^{\ddagger}$ & 1.00 (reference) & $1.43(0.63-3.26)$ & $1.71(0.73-4.01)$ \\
\hline \multicolumn{4}{|l|}{ Fish and shellfish } \\
\hline Not less than median/less than median ${ }^{\dagger}$ & $23 / 26$ & $30 / 29$ & $38 / 35$ \\
\hline Nonadjusted OR $(95 \% \mathrm{CI})$ & 1.00 (reference) & $1.17(0.55-2.50)$ & $1.23(0.59-2.53)$ \\
\hline Adjusted OR $(95 \% \mathrm{CI})^{\ddagger}$ & 1.00 (reference) & $1.23(0.53-2.89)$ & $2.69(1.07-6.77)$ \\
\hline \multicolumn{4}{|l|}{ Meat } \\
\hline Not less than median/less than median ${ }^{\dagger}$ & $23 / 26$ & $32 / 27$ & $36 / 37$ \\
\hline Nonadjusted OR $(95 \%$ CI $)$ & 1.00 (reference) & $1.34(0.63-2.86)$ & $1.10(0.53-2.27)$ \\
\hline Adjusted OR $(95 \% \mathrm{CI})^{\ddagger}$ & 1.00 (reference) & $1.21(0.55-2.67)$ & $0.93(0.41-2.12)$ \\
\hline \multicolumn{4}{|l|}{ Eggs } \\
\hline Not less than median/less than median ${ }^{\dagger}$ & $22 / 27$ & $28 / 31$ & $41 / 32$ \\
\hline Nonadjusted OR $(95 \% \mathrm{CI})$ & 1.00 (reference) & $1.11(0.52-2.37)$ & $1.57(0.76-3.26)$ \\
\hline Adjusted OR $(95 \% \mathrm{CI})^{\ddagger}$ & 1.00 (reference) & $1.13(0.51-2.50)$ & $1.42(0.62-3.24)$ \\
\hline \multicolumn{4}{|l|}{ Dairy products } \\
\hline Not less than median/less than median ${ }^{\dagger}$ & $27 / 22$ & $27 / 32$ & $37 / 36$ \\
\hline Nonadjusted OR $(95 \%$ CI $)$ & 1.00 (reference) & $0.69(0.32-1.47)$ & $0.84(0.41-1.73)$ \\
\hline Adjusted OR $(95 \% \mathrm{CI})^{\ddagger}$ & 1.00 (reference) & $0.76(0.35-1.69)$ & $1.01(0.44-2.32)$ \\
\hline \multicolumn{4}{|l|}{ Confectioneries } \\
\hline Not less than median/less than median ${ }^{\dagger}$ & $23 / 26$ & $32 / 27$ & $36 / 37$ \\
\hline Nonadjusted OR (95\% CI) & 1.00 (reference) & $1.34(0.63-2.86)$ & $1.10(0.53-2.27)$ \\
\hline Adjusted OR $(95 \% \mathrm{CI})^{\ddagger}$ & 1.00 (reference) & $1.37(0.62-3.03)$ & $0.75(0.33-1.71)$ \\
\hline
\end{tabular}

OR, odds ratio; CI, confidence interval.

* The subjects were asked the following question: "How much time per week did you usually spend on engaging in physical exercise or sports?" The results were self-reported according to the following five categories: " $<1 \mathrm{~h} / \mathrm{wk}$," "1-4 h/wk," "5-7 h/wk," "8-11 h/wk," and " $\geq 12 \mathrm{~h} /$ wk." For data analysis, 5-7 h/wk, 8-11 h/wk, and not less than $12 \mathrm{~h} /$ wk were combined into a " $\geq 5 \mathrm{~h} / \mathrm{wk}$ " group. The subjects were categorized as either "sedentary" ( $<1 \mathrm{~h} / \mathrm{wk})$, "moderate" (1-4 h/wk), or "active" ( $\geq 5 \mathrm{~h} / \mathrm{wk})$ according to regular exercise.

${ }^{\dagger}$ Median of food group intake is gender-specific (see Table 2).

$¥$ Adjusted for age (years, continuous), BMI ( $\mathrm{kg} / \mathrm{m}^{2}$, continuous), living alone (yes or no), and education (university, college, or technical school). 
ment after smoking cessation, or both. A previous study using the Food Choice Questionnaire, which measures the reported importance of nine factors that might influence food choice, revealed that health and weight control were significantly associated with the intake of fresh fruit and "healthy foods" such as white fish (33). Because exercise and the intake of fruit and fish are related to health consciousness, health consciousness could at least partially explain the association between regular exercise and the intake of fruits and fish observed in the present study. However, it is not clear whether regular exercise is affected by health consciousness when selecting food, since we didn't investigate any psychological measure in the current study.

Some studies have recently suggested that physical activity was associated with unhealthy dietary habits such as the consumption of fast food and savory snacks $(9,10,27,30)$. In a population-based study of Iranian children and adolescents, Kelishadi et al. showed that the level of physical activity had significant relationships with the intake of fast food, salty/fatty snacks, and sweets/candies (27). An additional study used data from the SPEEDY study, which revealed an association between an increased consumption of fizzy drinks and savory snacks and higher moderate-to-vigorous physical activity in British Caucasian children (9). Moreover, performing regular exercise does not necessarily result in decreased sedentary behavior (10); sedentary behavior, assessed as screen time and TV viewing, was also associated with unhealthy dietary behaviors in children, adolescents, and adults (34). In the present study, although unadjusted analyses revealed an association between regular exercise and confectionery intake in females, there was no such association after adjusted analysis.

The current study has several limitations. First, regular exercise and dietary intake were measured using selfreporting questionnaires. It is known that self-reported measures of physical activity are likely to contain errors of over-reporting due to social desirability (35). However, because previous studies revealed that physical activity estimated using a single-item question was correlated with measurements of physical activity using a validated questionnaire $(23,36)$, we consider a singleitem question to be a reliable measure for use in correlation analyses. Second, the subjects were students and not a random selection of Japanese young adults. Not all Japanese adolescents enter university, college, or technical school (enrollment rate $=53.2 \%$ ) (37), and those that do might have a different social and economic status. Therefore, our results cannot be readily extrapolated to the general population of Japanese young adults. Finally, although we attempted to adjust for potential confounders, we cannot completely exclude the effects of residual confounders.

In conclusion, the present findings suggested food group intakes associated with regular exercise in Japanese young adults. Further research needs to evaluate the food choice motives associated with regular exercise in order to reveal the reason for the association between regular exercise and dietary habits.

\section{Acknowledgments}

We are grateful to all the students for their generous participation in this study. We also thank our collaborators at each institution.

\section{Conflicts of interest}

The authors declare that they have no competing interests.

\section{REFERENCES}

1) Caspersen CJ, Powell KE, Christenson GM. 1985. Physical activity, exercise, and physical fitness: definitions and distinctions for health-related research. Public Health Rep 100: 126-131.

2) Windle G, Hughes D, Linck P, Russell I, Woods B. 2010. Is exercise effective in promoting mental well-being in older age? A systematic review. Aging Ment Health 14: 652-669.

3) Rosenbaum S, Sherringron C. 2011. Is exercise effective in promoting mental well-being in older age? A systematic review. Br J Sports Med 45: 1079-1080.

4) Hagen KB, Dagfinrud H, Moe RH, Østerås N, Kjeken I, Grotle M, Smedslund G. 2012. Exercise therapy for bone and muscle health: an overview of systematic reviews. BMC Med 19: 167-177.

5) Haskell WL, Lee IM, Pate RR, Powell KE, Blair SN, Franklin BA, Macera CA, Heath GW, Thompson PD, Bauman A. 2007. Physical activity and public health: updated recommendation for adults from the American College of Sports Medicine and the American Heart Association. Circulation 28: 1081-1093.

6) Hunter DJ, Reddy KS. 2013. Noncommunicable diseases. N Engl J Med 369: 1336-1343.

7) Ministry of Health, Labour and Welfare, Japan. 2013. Exercise and Physical Activity Reference for Health Promotion (EPAR) 2013. [Online]. Available: http://www0. nih.go.jp/eiken/info/pdf/sintai2013.pdf [accessed December 2, 2014] (in Japanese).

8) Ministry of Health, Labour and Welfare, Japan. 2012. The National Health and Nutrition Survey in Japan, 2012. [Online]. Available: http://www.mhlw.go.jp/ bunya/kenkou/eiyou/dl/h24-houkoku.pdf [accessed December 2, 2014] (in Japanese).

9) Vissers PAJ, Jones AP, van Sluijs EMF, Jennings A, Welch A, Cassidy A, Griffin SJ. 2013. Association between diet and physical activity and sedentary behaviours in 9-10-year-old British White children. Public Health 127: 231-240.

10) Al-Hazzaa HM, Abahussain NA, Al-Sobayel HI, Qahwaji DM, Musaiger AO. 2011. Physical activity, sedentary behaviors and dietary habits among Saudi adolescents relative to age, gender and region. Int J Behav Nutr Phys Act 8: 140-153.

11) Ottevaere C, Huybrechts I, Béghin L, Cuenca-Garcia M, De Bourdeaudhuij I, Gottrand F, Hagströmer M, Kafatos A, Le Donne C, Moreno LA, Sjöström M, Widhalm K, De Henauw S, HELENA (Healthy Lifestyle in Europe by Nutrition in Adolescence) Study Group. 2011. Relationship between self-reported dietary intake and physical activity levels among adolescents: the HELENA study. Int J Behav Nutr Phys Act 8: 8-16.

12) van Sluijs EM, Skidmore PM, Mwanza K, Jones AP, Callaghan AM, Ekelund U, Harrison F, Harvey I, Panter J, Wareham NJ, Cassidy A, Griffin SJ. 2008. Physical activ- 
ity and dietary behaviour in a population-based sample of British 10-year old children: the SPEEDY study (Sport, Physical activity and Eating behaviour: environmental Determinants in Young people). BMC Public Health 14: 388-399.

13) Pate RR, Sargent RG, Baldwin C, Burgess ML. 1990 Dietary intake of women runners. Int J Sports Med 11: 461-466.

14) Reggiani E, Bertolini S, Chiodini G, Elicio N, Montanari D, Valice S, Zannini G, Baruzzo D, Montagna G, Pistocchi G, Lassa G, Croce S. 1984. Effects of physical activity and diet on lipemic risk factors for atherosclerosis in women. Int J Sports Med 5: 183-186.

15) Elder SJ, Roberts SB. 2007. The effects of exercise on food intake and body fatness: a summary of published studies. Nutr Rev 65: 1-19.

16) Okubo H, Sasaki S. 2004. Underreporting of energy intake among Japanese women aged 18-20 years and its association with reported nutrient and food group intakes. Public Health Nutr 7: 911-917.

17) Tabata I, Ebine N, Kawashima Y, Ishikawa-Takata K, Tanaka S, Higuchi M, Yoshitake Y. 2013. Dietary reference intakes for Japanese 2010: energy. J Nutr Sci Vitaminol 59(Suppl): S26-S35.

18) Sasaki S, Yanagibori R, Amano K. 1998. Self-administered diet history questionnaire development for health education: a relative validation of the test-version by comparison with 3-day diet record in women. J Epidemiol 8: 203-215.

19) Sasaki S, Yanagibori R, Amano K. 1998. Validity of a self-administered diet history questionnaire for assessment of sodium and potassium: comparison with single 24-hour urinary excretion. Jpn Circ J 62: 431-435.

20) Science and Technology Agency. 2005. Standard Tables of Food Composition in Japan, Fifth revised and enlarged edition. Tokyo (in Japanese).

21) Kobayashi S, Murakami K, Sasaki S, Okubo H, Hirota N, Notsu A, Fukui M, Date C. 2011. Comparison of relative validity of food group intakes estimated by comprehensive and brief-type self-administered diet history questionnaires against $16 \mathrm{~d}$ dietary records in Japanese adults. Public Health Nutr 14: 1200-1211.

22) Kobayashi S, Honda S, Murakami K, Sasaki S, Okubo H, Hirota N, Notsu A, Fukui M, Date C. 2012. Both comprehensive and brief-type self-administered diet history questionnaires have reasonable ranking ability for nutrient intakes compared with 16-day dietary records in Japanese adults. J Epidemiol 22: 151-159.

23) Iwai N, Hisamichi S, Hayakawa N, Inaba Y, Nagaoka T, Sugimori H, Seki N, Sakata K, Suzuki K, Tamakoshi A, Nakamura Y, Yamamoto A, Nishino Y, Ogihara A, Okamoto N, Suzuki H, Morioka S, Ito Y, Wakai K, Ojima T, Tanaka H, Nose T, Ohno Y. 2001. Validity and reliability of single-item questions about physical activity. J Epidemiol 11: 211-218.

24) Iso H, Kobayashi M, Ishihara J, Sasaki S, Okada K, Kita Y, Kokubo Y, Tsugane S; JPHC Study Group. 2006. Intake of fish and $\mathrm{n} 3$ fatty acids and risk of coronary heart dis- ease among Japanese: the Japan Public Health CenterBased (JPHC) Study Cohort I. Circulation 113: 195-202.

25) Takachi R, Inoue M, Ishihara J, Kurahashi N, Iwasaki M, Sasazuki S, Iso H, Tsubono Y, Tsugane S; JPHC Study Group. 2008. Fruit and vegetable intake and risk of total cancer and cardiovascular disease: Japan Public Health Center-Based Prospective Study. Am J Epidemiol 167: 59-70.

26) Bibiloni Mdel M, Pich J, Córdova A, Pons A, Tur JA. 2012. Association between sedentary behaviour and socioeconomic factors, diet and lifestyle among the Balearic Islands adolescents. BMC Public Health 30: $718-729$.

27) Kelishadi R, Ardalan G, Gheiratmand R, Gouya MM, Razaghi EM, Delavari A, Majdzadeh R, Heshmat R, Motaghian M, Barekati H, Mahmoud-Aravi MS, Riazi MM, CASPIAN Study Group. 2007. Association of physical activity and dietary behaviours in relation to the body mass index in a national sample of Iranian children and adolescents: CASPIAN study. Bull World Health Organ 85: 19-26.

28) Oppert JM, Thomas F, Charies MA, Benetos A, Basdevant A, Simon C. 2006. Leisure-time and occupational physical activity in relation to cardiovascular risk factors and eating habits in French adults. Public Health Nutr 9: 746-754.

29) Jago R, Nicklas T, Yang SJ, Baranowski T, Zakeri I, Berenson GS. 2005. Physical activity and health enhancing dietary behaviors in young adults: Bogalusa Heart Study. Prev Med 41: 194-202.

30) Morin P, Turcotte S, Perreault G. 2013. Relationship between eating behaviors and physical activity among primary and secondary school students: results of a cross-sectional study. J Sch Health 83: 597-604.

31) Prochaska JJ, Spring B, Nigg CR. 2008. Multiple health behavior change research: An introduction and overview. Prev Med 46: 181-188.

32) Nagaya T, Yoshida H, Takahashi H, Kawai M. 2007. Cigarette smoking weakens regular exercise in healthy men. Nicotine Tob Res 9: 1027-1032.

33) Pollard TM, Steptoe A, Wardle J. 1998. Motives underlying healthy eating: using the Food Choice Questionnaire to explain variation in dietary intake. J Biosoc Sci 30: 165-179.

34) Pearson N, Biddle SJH. 2011. Sedentary behavior and dietary intake in children, adolescents, and adults: a systematic review. Am J Prev Med 41: 178-188.

35) Motl RW, McAuley E, DiStefano C. 2005. Is social desirability associated with self-reported physical activity? Prev Med 40: 735-739.

36) Milton K, Bull FC, Bauman A. 2011. Reliability and validity testing of a single-item physical activity measure. Br J Sports Med 45: 203-208.

37) Ministry of Education, Culture, Sports, Science and Technology, Japan. 2013. General survey of schools. [Online]. Available: http://www.mext.go.jp/component/b_menu/ other/_icsFiles/afieldfile/2013/12/20/1342607_2. pdf [accessed December 2, 2014] (in Japanese). 